\title{
Correction: Developing Thin Clients Using Amphibious Epistemologies
}

\section{Josiah Carberry \\ Department of Psychoceramics, Brown University}

http://dx.doi.org/10.5555/25252525x

\section{Correction Notice}

The title of the article, "Developing Thin Clients Using Amphibious Epistemologies" should have read "Developing Thin Clients Using Ambiguous Epistemologies"

Sorry about that. The copyeditor has been shot. 